\title{
Efficacy and HCC development after DAA therapy for patients with chronic hepatitis C: a single center retrospective cohort study
}

\author{
Akitoshi Douhara, Hiroyuki Ogawa, Satoshi Nakatani, Takahiro Ozutsumi, Erika Shioyama, Masaaki Yoshikawa, \\ Shigehiko Ueda
}

Internal Medicine, Kokuho Central Hospital 404-1, Miyako, Tawaramoto-cho, Shiki-gun, Nara Prefecture 636-0302, Japan.

Correspondence to: Dr. Akitoshi Douhara, Internal Medicine, Kokuho Central Hospital 404-1, Miyako, Tawaramoto-cho, Shiki-gun, Nara Prefecture 636-0302, Japan. E-mail: aki-do@hotmail.co.jp

How to cite this article: Douhara A, Ogawa H, Nakatani S, Ozutsumi T, Shioyama E, Yoshikawa M, Ueda S. Efficacy and HCC development after DAA therapy for patients with chronic hepatitis C: a single center retrospective cohort study. Hepatoma Res 2017;3:215-20.

Article history:

Received: 28 Jul 2017

Accepted: 20 Sep 2017

Published: 17 Oct 2017

\section{Key words:}

Chronic hepatitis C,

direct-acting antiviral therapy,

development of hepatocellular

carcinoma,

sarcoidosis

\begin{abstract}
Aim: The development of hepatocellular carcinoma (HCC) is reduced after interferon based treatment in patients with chronic hepatitis $\mathrm{C}(\mathrm{CHC})$. A new therapy using direct-acting antiviral agents (DAA) has been widely applied since 2014 for CHC. The purpose of this study is to investigate the efficacy, safety and development of HCC after DAA treatment. Methods: The authors enrolled 33 consecutive patients who were treated with DAA for CHC at the hospital between January 2015 and March 2016. The laboratory data were collected at the start and 24 weeks after DAA therapy. Results: The authors analyzed 33 patients (18 male, 15 female, mean age of 68 -year-old). The hepatic $\mathrm{C}$ virus genotypes were type 1 (27 patients) and type 2 (6 patients). The number of patients treated with sofosbuvir (SOF) + ledipasvir, daclatasvir + asunaprevir and SOF + ribavirin was 14, 13 and 6, respectively. The sustained virological response (SVR24) rate was 100\%. Aspartate aminotransferase, alanine aminotransferase and FIB4-index were significantly decreased after SVR24. Adverse effects were observed in 9 patients (anemia, 5; liver function test disorder, 2; sarcoidosis, 1; pruritus, 1). With regard to HCC development, one elderly patient (3.0\%) had multiple HCC recurrence after SVR24. Conclusion: DAA therapy achieved a high SVR24 rate with a good serological response. However, one patient had multiple HCC recurrence. These findings indicate that careful follow-up may be essential after DAA therapy.
\end{abstract}

\section{INTRODUCTION}

During the previous decades, Pegylated interferon (PEG-IFN) plus ribavirin therapy for patients with chronic hepatitis $\mathrm{C}(\mathrm{CHC})$ cured hepatic $\mathrm{C}$ virus $(\mathrm{HCV})$ infection in approximately $50 \%$ of treated patients ${ }^{[1]}$. Emerging treatments with IFN-free direct-acting antiviral agents
(DAA) for patients with chronic $\mathrm{CHC}$ directly target $\mathrm{HCV}$ replication and have been widely used globally since 2014. Compared to conventional IFN-therapy, the sustained virological response (SVR) rate is higher and the side effects are reduced with DAA therapy. Previously, it was reported that IFN-based therapy reduced the risk of liver complications, including the

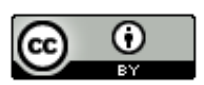

This is an open access article licensed under the terms of Creative Commons Attribution 4.0 International License (https://creativecommons.org/licenses/by/4.0/), which permits unrestricted use, distribution, and reproduction in any medium, as long as the original author is credited and the new creations are licensed under the identical terms.

For reprints contact: service@oaepublish.com

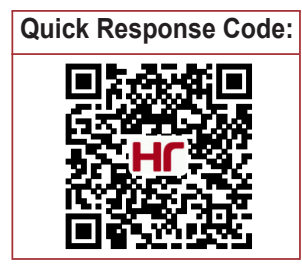


occurrence of hepatocellular carcinoma $(\mathrm{HCC})^{[2-4]}$. However, these results were supported by studies with only IFN-based regimens. Thus, it is unclear whether DAA therapy reduces the occurrence of $\mathrm{HCC}$.

The aim of this study was to evaluate the safety, efficacy and HCC development after DAA therapy in patients with $\mathrm{CHC}$.

\section{METHODS}

\section{Patients}

In this retrospective cohort study, we analyzed data from consecutive patients with $\mathrm{CHC}$ who were treated with DAA therapy at our hospital in the middle south area of Nara prefecture, Japan, between January 2015 and March 2016 [Figure 1]. All data were obtained from individual patient records at our hospital. The eligibility of each patient for the treatment of HCV with DAA therapy was assessed following the criteria established by the Japan society of hepatology. The criteria for treatment included: patients with chronic hepatitis or Child-Pugh class A liver cirrhosis with no evidence of HCC as confirmed by ultrasound sonography (US) and/or contrast-enhanced computed tomography (CT)/magnetic resonance imaging (MRI). At the end of therapy and at 24 weeks off therapy, liver function was estimated again. The virological response to DAA therapy was assessed by quantitative HCV-RNA detection using real-time polymerase chain reaction. At 24 weeks off therapy, patients underwent another abdominal ultrasound evaluation. If focal lesions of the liver were detected by US, patients were reevaluated with $\mathrm{CE}-\mathrm{CT} / \mathrm{MRI}$ to assess the occurrence or recurrence of HCC.

\section{Statistics}

Bivariate analyses of continuous variables were

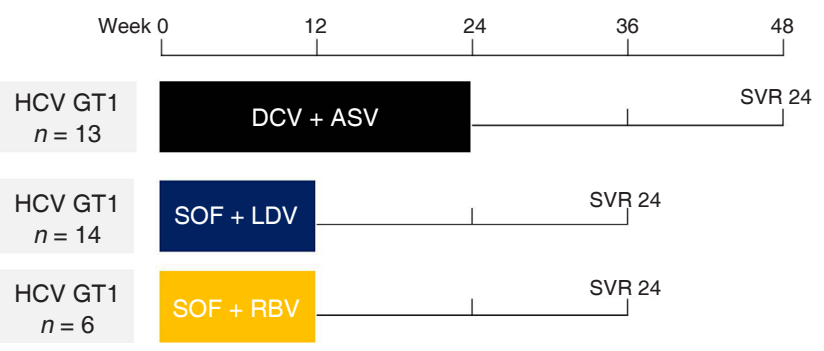

Figure 1: A total of 33 consecutive patients were treated with DAA for CHC at our hospital between January 2015 and March 2016. Patients were divided into a DCV + ASV group, an SOF + LDV group and an SOF + RBV group consisting of 13, 14 and 6 patients, respectively. The laboratory data were collected at the start and after 24 weeks of DAA therapy. HCC development was estimated by ultrasound sonography and/or CE-CT; DAA: directacting antiviral agents; CHC: chronic hepatitis C; DCV: daclatasvir; ASV: asunaprevir; SOF: sofosbuvir; LDV: ledipasvir; RBV: ribavirin; CE-CT: contrast-enhanced computed tomography performed using the Wilcoxon rank-sum test. A $P$ value of $<0.05$ was deemed statistically significant. All statistical analyses were performed using IBM SPSS statistics version 22 (IBM Corp., Armonk, NY, USA).

\section{RESULTS}

\section{Baseline characteristics of patients}

Between January 2015 and March 2016, a total of 33 patients received DAA therapy. All patients were followed for 24 weeks after DAA treatment. Table 1 shows the principle baseline characteristics of this study.

\section{Virological response}

Sustained virological response after 24 weeks (SVR24) was achieved in all patients $(100 \%)$, regardless of genotype 1 or 2 [Figure 2].

\section{Serological response}

Aspartate aminotransferase (AST) and alanine aminotransferase (ALT) indicated significantly decreased liver inflammation after SVR24. The FIB4-index, which is a calculated hepatic fibrosis marker, was also significantly decreased. Moreover, alpha $(\alpha)$-fetoprotein, which showed both liver inflammation and tumor marker, was significantly decreased. However, total bilirubin (T-bil), albumin and platelet count were not significantly changed after SVR24 [Table 2].

\section{Adverse events}

Liver function disorder was only observed in the daclatasvir (DCV) + Asunaprevir (ASV) group. Anemia was found only in the sofosbuvir (SOF) + ribavirin (RBV) group [Table 3]. One patient treated with SOF +

Table 1: The principle baseline characteristics of the study, $n=33$

\begin{tabular}{lc}
\hline Characteristics & $\boldsymbol{n}(\%)$ \\
\hline Mean age, year (range) & $68(41-83)$ \\
Male & $18(54.5)$ \\
Japanese & $33(100)$ \\
History of IFN therapy & $20(60.6)$ \\
HCV-RNA, log IU/mL (range) & $6.0(4.5-7.1)$ \\
HCV GT1 & $27(81.8)$ \\
GT2 & $6(18.2)$ \\
Cirrhosis & $8(24.2)$ \\
Platelet $\left(10^{4} \mathrm{~mm}^{3}\right.$ ) & $14.4 \pm 4.5$ \\
Aspartate aminotransferase (IU/L) & $43 \pm 20$ \\
Alanine aminotransferase (IU/L) & $46 \pm 29$ \\
T-bil (mg/dL) & $0.8 \pm 0.3$ \\
Albumin $(\mathrm{g} / \mathrm{dL})$ & $4.1 \pm 0.3$ \\
AFP (ng/mL) & $11.1 \pm 19.0$ \\
FIB4 Index & $3.6 \pm 2.6$ \\
\hline
\end{tabular}

Data are reported as the mean $\pm \mathrm{SD}$. HCV: hepatic C virus; T-bil: total bilirubin; AFP: Alpha-fetoprotein; IFN: interferon 


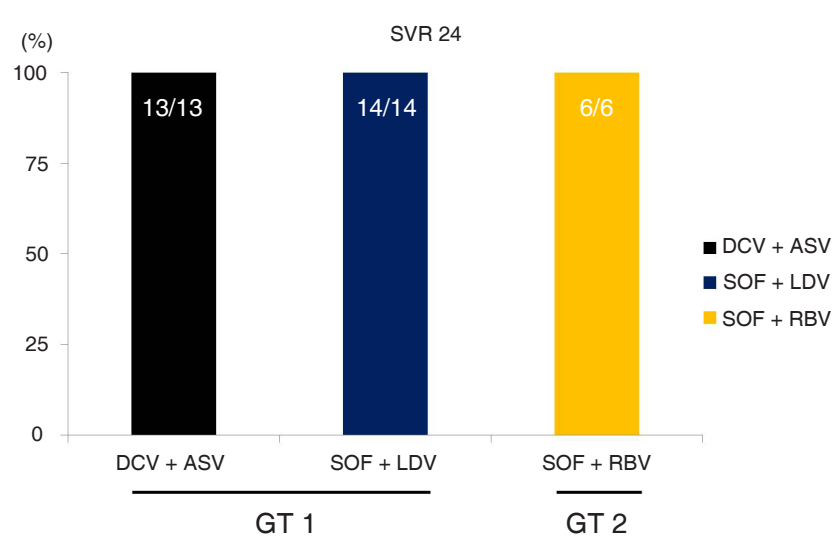

Figure 2: SVR24 rate with GT1 or GT2. All patients achieved SVR24 regardless of GT1 or GT2. SVR: sustained virological response; DCV: daclatasvir; ASV: asunaprevir; SOF: sofosbuvir; LDV: ledipasvir; RBV: ribavirin

Table 2: Virological response before and 24 weeks following therapy

\begin{tabular}{lccc}
\hline Characteristics & Baseline & $\begin{array}{c}\text { 24 weeks } \\
\text { off therapy }\end{array}$ & $\boldsymbol{P}$ \\
\hline AST $(\mathrm{IU} / \mathrm{L})$ & $43 \pm 20$ & $22 \pm 5$ & 0.000 \\
ALT $(\mathrm{IU} / \mathrm{L})$ & $46 \pm 29$ & $17 \pm 5$ & 0.000 \\
T-bil $(\mathrm{mg} / \mathrm{dL})$ & $0.8 \pm 0.3$ & $0.8 \pm 0.3$ & 0.094 \\
Albumin $(\mathrm{g} / \mathrm{dL})$ & $4.1 \pm 0.3$ & $4.3 \pm 0.2$ & 0.081 \\
Platelet $\left(10^{4} \mathrm{x} / \mathrm{mm}^{3}\right)$ & $14.4 \pm 4.5$ & $15.1 \pm 4.3$ & 0.125 \\
AFP $(\mathrm{ng} / \mathrm{mL})$ & $11.1 \pm 19.0$ & $6.0 \pm 13.1$ & 0.000 \\
FIB4-index & $3.6 \pm 2.6$ & $2.6 \pm 1.3$ & 0.000 \\
\hline
\end{tabular}

AST, ALT, AFP and FIB4-index were significantly decreased. However, T-bil, albumin and platelet count were not significantly changed after SVR24. AST: aspartate aminotransferase; ALT: alanine aminotransferase; T-bil: total bilirubin; AFP: alphafetoprotein

ledipasvir (LDV) developed sarcoidosis after SVR24 [Figure 3]; after the end of DAA treatment, renal dysfunction occurred. Renal biopsy revealed renal sarcoidosis. Moreover, chest X-P showed bilateral hilar lymphadenopathy while the ophthalmologic examination showed iritis. Eradication of HCV or DAA treatment itself might trigger the onset of sarcoidosis.

\section{HCC development}

With regard to HCC development, patients without an HCC history did not develop HCC in these observed periods [Table 4]. One elderly patient (3.0\%) had multiple
Table 4: HCC development after DAA therapy, $n=33$

\begin{tabular}{lc}
\hline HCC development & $\boldsymbol{n}(\%)$ \\
\hline HCC pre-treatment (+) & \\
HCC occurrence (+) & $1(3.0)$ \\
HCC occurrence (-) & 0 \\
HCC history(-) & 0 \\
HCC occurrence (+) & $32(97)$ \\
HCC occurrence (-) & $10.4 \pm 3.7$ \\
Observed periods after DAA, month
\end{tabular}

Patients without HCC history did not develop HCC in these observed periods. One elderly patient $(3.0 \%)$ had multiple HCC recurrence after SVR24. HCC: hepatocellular carcinoma; DAA: direct-acting antiviral agents

HCC recurrence after SVR24 [Figure 4]. Before the start of DAA treatment, transarterial chemoembolization (TACE) was performed twice. Then, DAA treatment was initiated after a complete response was achieved. CE-CT after 3 months from the end of DAA treatment showed local and distant HCC recurrence. Common hepatic artery angiography showed multiple HCC. Thus, a 3rd TACE was performed for HCC recurrence.

\section{DISCUSSION}

IFN-based therapy for $\mathrm{CHC}$ should not be used for elderly patients and autoimmune diseases because of adverse effects and the mechanism of IFN. On the other hand, DAA therapy can be used for these patients with relative safety. However, as DAA therapy is relatively new, it is unclear whether DAA therapy ameliorates hepatic fibrosis and suppresses the development of HCC. Thus, the purpose of this retrospective cohort study was to elucidate changes in liver function and fibrotic markers before and after DAA therapy using SVR24, adverse events and HCC development.

The effect for SVR24 was very high in this cohort study. The SVR rate of DCV + ASV is known to be slightly lower than SOF + LDV. We checked the resistance associated substitution (RAS) before DCV + ASV administration. All DCV + ASV patients didn't have Y93 mutation, which was key mutation involving for non-SVR. In our speculation, the reasons of the high SVR24 rate of DCV + ASV group may be wild type of RAS and the small number of patients (DCV + ASV, $n=13)$.

Table 3: Adverse events during and after DAA therapy

\begin{tabular}{lccc}
\hline Adverse events & DCV + ASV $\boldsymbol{n = 1 3}$ & SOF + LDV $\boldsymbol{n = 1 4}$ & SOF + RBV $\boldsymbol{n}=\mathbf{6}$ \\
\hline Anemia & 0 & 0 & Grade1, 2(33.3\%) \\
Grade 2, 3 (50\%) \\
Liver function test disorder & Grade1, $1(7.7 \%)$ & 0 & 0 \\
Pruritus & Grade3, $1(7.7 \%)$ & 0 & 0 \\
Sarcoidosis & $1(7.7 \%)$ & $1(7.1 \%)$ & 0 \\
\hline
\end{tabular}

Liver function disorder was found in only the DCV + ASV group. Anemia was found in only the SOF + RBV group. One patient treated with SOF + LDV developed sarcoidosis after SVR24. DCV: daclatasvir; ASV: asunaprevir; SOF: sofosbuvir; RBV: ribavirin; LDV: ledipasvir; SVR: sustained virological response 
$\left(\mathrm{mL} / \mathrm{min} / 1.73 \mathrm{~m}^{2}\right)$
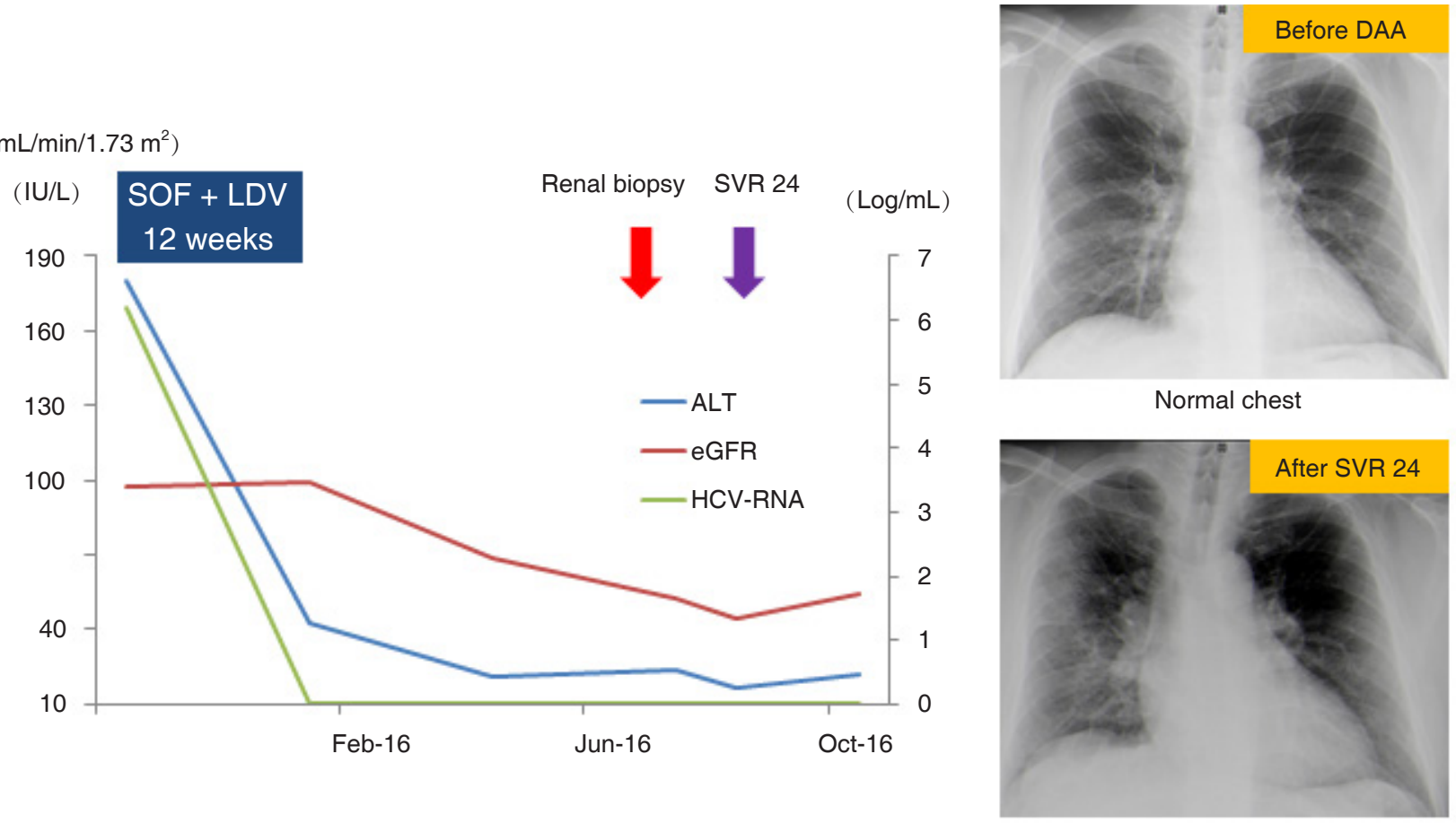

$\mathrm{BHL}$

Figure 3: A case of sarcoidosis after DAA treatment. A 46-year-old male. After the end of DAA treatment, renal dysfunction occurred. Renal biopsy revealed renal sarcoidosis. Moreover, chest X-P showed BHL while the ophthalmologic examination showed iritis. The eradication of HCV or the DAA treatment itself might have triggered the onset of sarcoidosis. DAA: direct-acting antiviral; BHL: bilateral hilar lymphadenopathy; HCV: hepatic C virus; SOF: sofosbuvir; LDV: ledipasvir; SVR: sustained virological response

$(\mathrm{ng} / \mathrm{mL})$

(IU/L) TACE 1st TACE 2nd

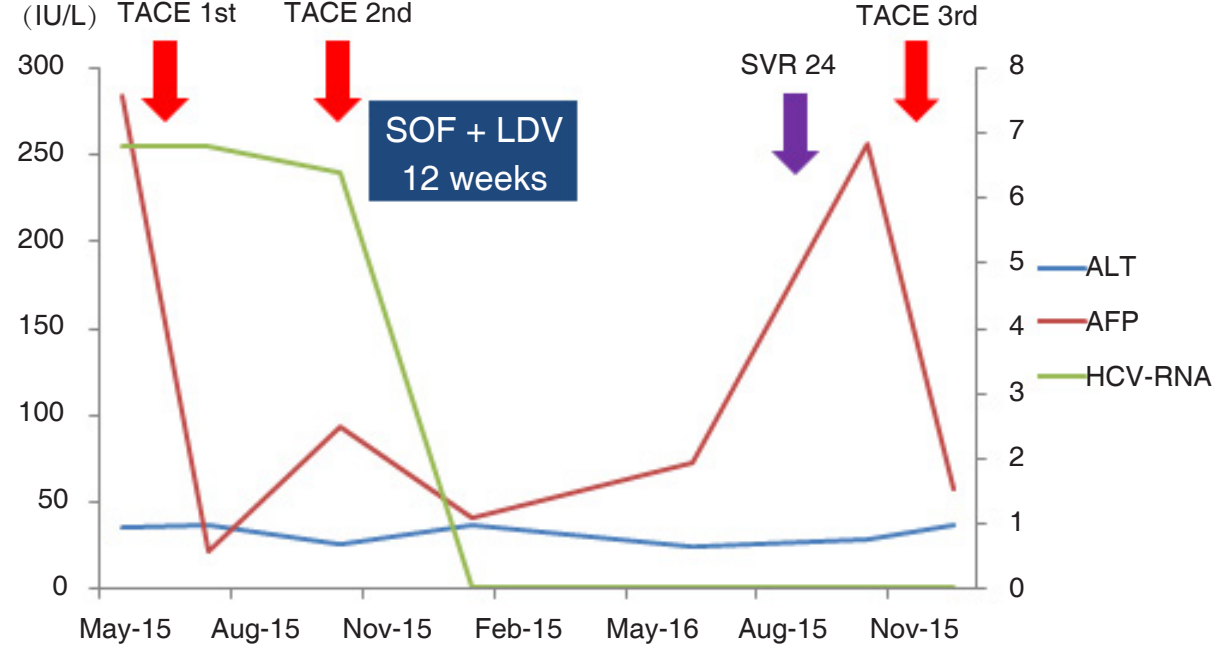

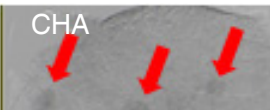
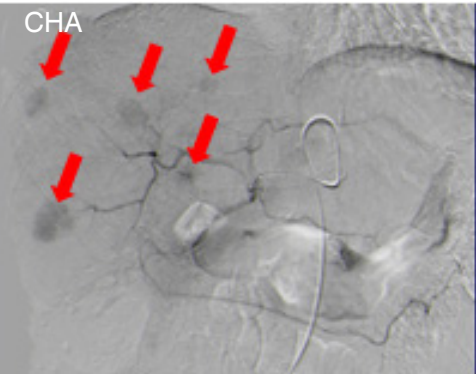

CHA angiography showed multiple HCC (arrow)

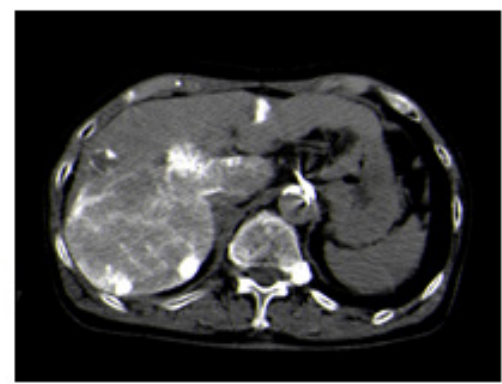

3rd C-TACE was performed

Figure 4: A case of HCC development after DAA treatment. A 81-year-old male. Before the start of DAA treatment, TACE was performed twice. Then, DAA treatment was initiated after a complete response was achieved. CE-CT after 3 months from the end of DAA treatment showed local and distant HCC recurrence. CHA angiography showed multiple HCC. Thus, a 3rd TACE was performed for HCC recurrence. HCC: hepatocellular carcinoma; DAA: direct-acting antiviral; TACE: transarterial chemoembolization; CT: computed tomography; SOF: sofosbuvir; LDV: ledipasvir; ALT: alanine aminotransferase; AFP: alpha-fetoprotein; HCV: hepatic C virus; SVR: sustained virological response 
In the IFN era, liver fibrosis was improved after SVR in patients with $\mathrm{CHCC}^{[4-6]}$. Shiratori et al. ${ }^{[3]}$ reported that the resolution of hepatic fibrosis was achieved in 0.283 stages per year. However, whether anti-fibrotic effects occurred with DAA therapy was unclear. In our study, platelet count, T-bil and albumin were unchanged, likely because the observed period was only six month after the end of DAA treatment. However, AST and ALT, which showed that liver inflammation was significantly decreased, as well as the FIB4-index, which is a calculated hepatic fibrosis marker, were significantly decreased after SVR24.

IFN-based treatment for $\mathrm{CHC}$ has multiple adverse events, such as influenza like syndrome, interstitial pneumonia, cytopenia, depression, etc. Conversely, DAA therapy rarely has adverse events compared to IFN-based treatment. ASV, an NS3/4 protease inhibitor, is more likely to result in liver function test disorder ${ }^{[7]}$. In our study, 2 patients in the DCV + ASV group $(n=$ 13) had liver function disorder [Grade $1, n=1(7.7 \%)$; Grade 3, $n=1(7.7 \%)]$. One patient withdrew from DAA therapy. Another patient decreased their dosage of ASV. Fortunately, these two patients achieved SVR24.

RBV + PEG-IFN therapy was used for patients with $\mathrm{CHC}$. It is known that ribavirin triggers hemolytic anemia ${ }^{[8]}$. In our study, the SOF + RBV group $(n=6)$ had anemia in 5 patients [Grade 1, $n=2$ (33.3\%); Grade 2, $n=3$ $(50 \%)]$. If anemia developed, we decreased the dosage of RBV. After the end of DAA treatment, anemia was naturally improved without blood transfusion or iron pill administration.

IFN is one of the cytokines in response to several pathogens, such as virus, bacteria, parasite and tumor. So, IFN therapy activated immune systems that help to eradicate HCV. The previous report indicated that IFN therapy for $\mathrm{CHC}$ triggered sarcoidosis via activating immune system ${ }^{[9-11]}$. Sarcoidosis is a granulomatous autoimmune disease of unknown etiology that may affect many organs. Until now, IFN was thought to be involved in the onset of sarcoidosis. In the other hands, DAA itself don't influence immune system. Moreover, $\mathrm{HCV}$ is known to have several systemic autoimmune disorder, such as cryoglobulinemia, Sjögren's syndrome, diabetes mellitus, thyroiditis, membranoproliferative glomerulonephritis, etc. Interestingly, in our study, the SOF + LDV group $(n=14)$ had a patient with lung and renal sarcoidosis that was induced after DAA therapy. Our case indicated that the eradication of HCV itself might have induced sarcoidosis via an acute change in immune status. In speculation, HCV decrease with the very short periods may trigger acute change in immune status.
With regard to the effect on HCC reoccurrence, the PEGIFN + RBV combination therapy reduced $\mathrm{HCC}$ occurrence if SVR was achieved ${ }^{[12-14]}$. In Italy, Bruno et al. ${ }^{[15]}$ reported that the SVR to IFN- $\alpha$ was associated with improved outcomes in HCV-related cirrhosis. Moreover, IFN itself has an anti-tumor effect ${ }^{[16]}$, and low-dose and long-term maintenance administration of PEG-IFNa-2a decreased the incidence of HCC in non-SVR patients ${ }^{[17]}$. On the other hand, DAA has no direct anti-tumor effect, and the suppressive effect of DAA on HCC occurrence remains controversial in western countries ${ }^{[18-21]}$. In a Japanese retrospective cohort study, the HCC risk rate after SVR was similar regardless of whether it was achieved by DAA or IFN-based regimens ${ }^{[22]}$. In our study, during a median follow-up period of $10.4 \pm 3.7$ months, one elderly patient (3.0\%) with an HCC history developed multiple HCC recurrence after SVR24. Patients without HCC history did not develop HCC in this observed period.

This study has several limitations. First, this was a single-center study with a limited number of patients. Therefore, the statistical power was low. Second, all patients in this study were Japanese. Thus, applying these results to other ethnic groups is difficult. Third, the criteria of liver function for DAA therapy in Japan are only CPS grade A. Therefore, the efficacy and safety of DAA therapy in patients with CPS grades from $B$ to $C$ are unknown.

In conclusion, DAA therapy achieved a high SVR rate and a good serological response. However, one patient had multiple HCC recurrence in our small cohort study. These findings indicate that careful follow-up may be essential after DAA therapy.

\section{DECLARATIONS}

\section{Authors' contributions}

Designed the report: A. Douhara

Attending doctors for patients: A. Douhara, H. Ogawa, E. Shioyama, M. Yoshikawa, S. Ueda

Discussed the pathogenesis: A. Douhara, H. Ogawa, S. Nakatani, T. Ozutsumi, E. Shioyama, M. Yoshikawa, S. Ueda

Organized the report: S. Ueda

Wrote the paper: A. Douhara

\section{Financial support and sponsorship} None.

\section{Conflicts of interest}

There are no conflicts of interest.

\section{Patient consent}

In our institution, we obtained informed consent from 


\section{each case as medical care.}

\section{Ethics approval}

This study conforms to the ethical guidelines of the Helsinki Declaration. The approved number of the institutional review board (IRB) is 72 .

\section{REFERENCES}

1. Fried MW, Shiffman ML, Reddy KR, Smith C, Marinos G, Gonçales FL Jr, Häussinger D, Diago M, Carosi G, Dhumeaux D, Craxi A, Lin A, Hoffman J, Yu J. Peginterferon alfa-2a plus ribavirin for chronic hepatitis C virus infection. N Engl J Med 2002;347:975-82.

2. Morgan RL, Baack B, Smith BD, Yartel A, Pitasi M, Falck-Ytter $\mathrm{Y}$. Eradication of hepatitis $\mathrm{C}$ virus infection and the development of hepatocellular carcinoma: a meta-analysis of observational studies. Ann Intern Med 2013;158:329-37.

3. Shiratori Y, Imazeki F, Moriyama M, Yano M, Arakawa Y, Yokosuka O, Kuroki T, Nishiguchi S, Sata M, Yamada G, Fujiyama S, Yoshida H, Omata M. Histologic improvement of fibrosis in patients with hepatitis $\mathrm{C}$ who have sustained response to interferon therapy. Ann Intern Med 2000;132:517-24.

4. Cammà C, Di Bona D, Schepis F, Heathcote EJ, Zeuzem S, Pockros PJ, Marcellin P, Balart L, Alberti A, Craxì A. Effect of peginterferon alfa-2a on liver histology in chronic hepatitis $\mathrm{C}$ : a meta-analysis of individual patient data. Hepatology 2004;39:333-42.

5. Poynard T, McHutchison J, Manns M, Myers RP, Albrecht J. Biochemical surrogate markers of liver fibrosis and activity in a randomized trial of peginterferon alfa- $2 \mathrm{~b}$ and ribavirin. Hepatology 2003;38:481-92.

6. Heathcote EJ, Shiffman ML, Cooksley WG, Dusheiko GM, Lee SS, Balart L, Reindollar R, Reddy RK, Wright TL, Lin A, Hoffman J, De Pamphilis J. Peginterferon alfa-2a in patients with chronic hepatitis C and cirrhosis. N Engl J Med 2000;343:1673-80.

7. Kumada H, Suzuki Y, Ikeda K, Toyota J, Karino Y, Chayama K, Kawakami Y, Ido A, Yamamoto K, Takaguchi K, Izumi N, Koike K, Takehara T, Kawada N, Sata M, Miyagoshi H, Eley T, McPhee F, Damokosh A, Ishikawa H, Hughes E. Daclatasvir plus asunaprevir for chronic HCV genotype 1b infection. Hepatology 2014;59:2083-91.

8. Soota K, Maliakkal B. Ribavirin induced hemolysis: a novel mechanism of action against chronic hepatitis $\mathrm{C}$ virus infection. World J Gastroenterol 2014;20:16184-90.

9. Kim SK, Kim SR, Imoto S, Kim CW, Hayashi Y. Sudden-onset sarcoidosis with severe dyspnea developing during pegylated interferon and ribavirin combination therapy for chronic hepatitis C. Turk J Gastroenterol 2017;28:75-6.

10. Buss G, Cattin V, Spring P, Malinverni R, Gilliet M. Two cases of interferon-alpha-induced sarcoidosis Koebnerized along venous drainage lines: new pathogenic insights and review of the literature of interferon-induced sarcoidosis. Dermatology 2013;226:289-97.

11. Joshita S, Shirahata K, Yazaki Y, Okaniwa S, Nakamura Y, Kimura T, Noami S, Horigome R, Yagi H, Ito N, Yamazaki A, Akahane Y, Umemura T, Yoshizawa K, Tanaka E, Ota M. Cutaneous sarcoidosis in a chronic hepatitis $\mathrm{C}$ patient receiving pegylated interferon and ribavirin therapy. Hepatol Res 2013;43:801-7.

12. Hung CH, Lee CM, Lu SN, Wang JH, Hu TH, Tung HD, Chen $\mathrm{CH}$, Chen WJ, Changchien CS. Long-term effect of interferon alpha$2 \mathrm{~b}$ plus ribavirin therapy on incidence of hepatocellular carcinoma in patients with hepatitis C virus-related cirrhosis. $J$ Viral Hepat 2006;13:409-14

13. Velosa J, Serejo F, Marinho R, Nunes J, Glória H. Eradication of hepatitis $\mathrm{C}$ virus reduces the risk of hepatocellular carcinoma in patients with compensated cirrhosis. Dig Dis Sci 2011;56:1853-61.

14. Floreani A, Baldo V, Rizzotto ER, Carderi I, Baldovin T, Minola E Pegylated interferon alpha- $2 \mathrm{~b}$ plus ribavirin for naive patients with HCV-related cirrhosis. J Clin Gastroenterol 2008;42:734-7.

15. Bruno $\mathrm{S}$, Stroffolini T, Colombo M, Bollani S, Benvegnù L, Mazzella G, Ascione A, Santantonio T, Piccinino F, Andreone P, Mangia A, Gaeta GB, Persico M, Fagiuoli S, Almasio PL; Italian Association of the Study of the Liver Disease (AISF). Sustained virological response to interferon-alpha is associated with improved outcome in HCVrelated cirrhosis: a retrospective study. Hepatology 2007;45:579-87.

16. Hisaka T, Yano H, Ogasawara S, Momosaki S, Nishida N, Takemoto Y, Kojiro S, Katafuchi Y, Kojiro M. Interferon-alphaCon1 suppresses proliferation of liver cancer cell lines in vitro and in vivo. $J$ Hepatol 2004:41:782-9.

17. Izumi N, Asahina Y, Kurosaki M, Yamada G, Kawai T, Kajiwara E, Okamura Y, Takeuchi T, Yokosuka O, Kariyama K, Toyoda J, Inao M, Tanaka E, Moriwaki H, Adachi H, Katsushima S, Kudo M, Takaguchi K, Hiasa Y, Chayama K, Yatsuhashi H, Oketani M, Kumada H. Inhibition of hepatocellular carcinoma by PegIFN $\alpha-2 a$ in patients with chronic hepatitis $\mathrm{C}$ : a nationwide multicenter cooperative study. J Gastroenterol 2013;48:382-90.

18. Cheung MC, Walker AJ, Hudson BE, Verma S, McLauchlan J, Mutimer DJ, Brown A, Gelson WT, MacDonald DC, Agarwal K, Foster GR, Irving WL; HCV Research UK. Outcomes after successful direct-acting antiviral therapy for patients with chronic hepatitis $\mathrm{C}$ and decompensated cirrhosis. J Hepatol 2016;65:741-7.

19. ANRS collaborative study group on hepatocellular carcinoma (ANRS CO22 HEPATHER, CO12 CirVir and CO23 CUPILT cohorts). Lack of evidence of an effect of direct-acting antivirals on the recurrence of hepatocellular carcinoma: data from three ANRS cohorts. J Hepatol 2016;65:734-40.

20. Conti F, Buonfiglioli F, Scuteri A, Crespi C, Bolondi L, Caraceni P, Foschi FG, Lenzi M, Mazzella G, Verucchi G, Andreone P, Brillanti S. Early occurrence and recurrence of hepatocellular carcinoma in HCV-related cirrhosis treated with direct-acting antivirals. $J$ Hepatol 2016;65:727-33

21. Reig $M$, Mariño $Z$, Perelló $C$, Iñarrairaegui $M$, Ribeiro $A$, Lens $S$, Díaz A, Vilana R, Darnell A, Varela M, Sangro B, Calleja JL, Forns $\mathrm{X}$, Bruix J. Unexpected high rate of early tumor recurrence in patients with HCV-related HCC undergoing interferon-free therapy. J Hepatol 2016;65:719-26.

22. Kobayashi M, Suzuki F, Fujiyama S, Kawamura Y, Sezaki H, Hosaka T, Akuta N, Suzuki Y, Saitoh S, Arase Y, Ikeda K, Kumada H. Sustained virologic response by direct antiviral agents reduces the incidence of hepatocellular carcinoma in patients with $\mathrm{HCV}$ infection. J Med Virol 2017;89:476-83. 